\title{
Proposta de Rede de Caminhabilidade para o Município de Lorena (SP)
}

\author{
A importância da arborização e dos aspectos qualitativos nas \\ propostas de percursos pedonais urbanos.
}

\author{
Gabriela Katie Silva Morita ${ }^{1}$, Roberta Consentino Kronka Mülfarth ${ }^{2}$ \\ ${ }^{1}$ Idealizadora do Movimento VamoaPé, arquiteta e urbanista, especialista em planejamento e gestão de cidades, \\ gabrielaks.morita@gmail.com \\ 2 FAUUSP, Prof.a Dra., rkronka@usp.br
}

\begin{abstract}
RESUMO: Este trabalho apresenta dados qualitativos e quantitativos acerca do ambiente urbano no município de Lorena, São Paulo. O método utilizado para desenvolvimento da pesquisa baseia-se na tese de livre docência Proposta metodológica para avaliação ergonômica do ambiente urbano (Mülfarth,2017), que, por meio da observação e inquirição, avalia a ergonomia do ambiente urbano. Justificada pela proposta de intervenção e melhorias da infraestrutura urbana na região central da cidade, tem como objetivo proporcionar maior qualidade ao passeio público do município, oferecendo espaços urbanos com infraestrutura adequada, mais convidativos e que estimulem os pedestres a se apropriarem das ruas, também incentivando a maior utilização dos meios de transporte não motorizados, bem como o transporte público. Tornar os locais mais atrativos, com arborização e calçadas conectadas, favorece as sensações de conforto e segurança, trazendo uma nova percepção do usuário sobre o espaço, proporcionando maior bem-estar e prazer ao caminhar. É fundamental repensar o papel da arborização urbana, pois, em se tratando de grande parte dos municípios do país, é uma qualidade pouco percebida nos espaços públicos das cidades. Este atributo, essencial para proporcionar caminhabilidade, sustentabilidade, conforto, segurança e estética também têm notável contribuição para melhorias na qualidade do ar, auxiliando no combate à poluição.
\end{abstract}

PALAVRAS-CHAVE: Infraestrutura urbana, arborização urbana, espaços públicos, percepção do usuário e caminhabilidade.

\begin{abstract}
This work presents qualitative and quantitative data about the urban environment in the city of Lorena, São Paulo. The method used for the research development is based on the thesis Methodological proposal for ergonomic evaluation of the urban environment (Mülfarth, 2017), with whom, through observation and inquiry, assesses the ergonomics of the urban environment. Justified by the proposal for intervention and improvements in urban infrastructure in the central region of the city, it aims to provide greater quality to the city's public sidewalk, offering urban spaces with right infrastructure, more inviting that stimulate pedestrians to hijack the streets, also encouraging greater use of non-motorized transportation, as well as public transport. Making places more attractive, with trees and connected sidewalks, favours feelings of comfort and security, bringing a new perception of the user about the space, providing greater well-being and pleasure when walking. It is essential to rethink the role of urban afforestation, since, in the case of a large part of the country's municipalities, it is a quality little perceived in public spaces in cities. This attribute, essential to provide walkability, sustainability, comfort, safety and aesthetics, also has a notable contribution to improvements in air quality, helping to combat pollution.
\end{abstract}

KEYWORDS: Urban Infrastructure, urban afforestation, public spaces, user perception and walkability.

\section{PANORAMA GERAL DAS CIDADES E CARACTERIZAÇÃO DO PROBLEMA}

Após anos de mudanças nas preferências de estilo de vida de cada indivíduo, a transição da população rural para cidades teve seu auge em 2007, quando, pela primeira vez a população urbana superou a população rural no mundo. De acordo com dados da World Urbanization Prospects (ONU, 2018), mais pessoas vivem em áreas urbanas do que em áreas rurais, com $55 \%$ da população mundial residindo em áreas urbanas em 2018. No Brasil, o processo de êxodo rural se intensificou nas décadas de 1970 e 1980, momento em que trabalhadores do campo seguiram em direção às cidades pela busca de oportunidades de emprego (IBGE, 2010). Em 2010, a população urbana já era mais de cinco vezes maior comparada com a população rural (Censo IBGE, 2010). Somado à crescente urbanização das cidades, há também o apoio institucional supported by
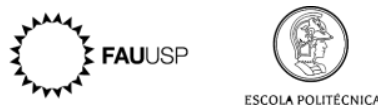
aumento desenfreado de veículos motorizados nas ruas, provocando congestionamento das vias públicas, piora na qualidade do ar devido a emissão de CO2, propagação e intensificação de ruídos sonoros, bem como estresse e interferência na saúde de cada indivíduo. Por isso, recuperar boas condições de passeio público nas cidades é essencial para reforçar a função social do espaço da cidade. Melhorias nas condições físicas do espaço urbano incentivam o caminhar; e é mais convidativo e seguro caminhar em uma rua movimentada, com diversas pessoas e comércios dialogando com o espaço público do que passar por uma rua deserta, ou com espaço voltado principalmente para automóveis. Espaços urbanos cheios de vitalidade, segurança, sustentabilidade e saúde estimulam as pessoas a permanecerem por mais tempo e de modo mais agradável na cidade, da mesma forma que, aumentando a rede de caminhos conectados para pedestres, e também a interligação de ciclovias, ciclorrotas ou ciclofaixas, também incentivará mais pessoas a caminhar ou pedalar.

A preocupação acerca do tema da caminhabilidade ainda é pouco mencionada no município de Lorena; são raros os trabalhos com essa temática, sendo um deles com a proposta de intervenção e melhorias da infraestrutura urbana na região central da cidade, a qual propunha como projeto a interligação de áreas arborizadas através de caminhos confortáveis com foco na acessibilidade de pessoas com deficiência e/ou mobilidade reduzida.

Southworth (2005, pg. 3) cita City of Boulder (2003) que diz "A viagem a pé está envolvida em todos os deslocamentos e é a base de todos os outros modos de locomoção." Quanto mais pessoas estiverem caminhando e permanecendo nos espaços urbanos, maior será a preservação e cuidado com o espaço, tornando-os mais seguros e agradáveis aos deslocamentos a pé. De acordo com Gehl (2010, pg. 91), sentir-se seguro é crucial para que as pessoas abracem o espaço urbano. Em geral, a vida e as próprias pessoas tornam a cidade mais convidativa e segura, seja em termos de segurança percebida ou vivenciada. Para Carvalho (2005) apud Gondim (2001) a adequação das vias para receber transporte motorizado pode interferir negativamente na circulação do transporte não motorizado, com o aumento da exposição do pedestre aos riscos das travessias; por essa razão os trechos analisados neste trabalho tiveram a preocupação com o pedestre como principal motivo da pesquisa.

\section{MÉTODOS E ESCOLHA DOS LOCAIS}

Os métodos de referência analisados expõem conceitos e atributos pensados no conforto do usuário em ambientes urbanos, colocando-o como protagonista no espaço das cidades visto que independente do modal de transporte utilizado com maior frequência por cada indivíduo, em algum momento todos ocupamos a posição de pedestre. Os métodos de Southworth, Pozueta, o Active Design, o Índice de caminhabilidade (ICam) do ITDP, e o método de avaliação ergonômica de Kronka Mülfarth foram as metodologias analisadas no desenvolvimento deste trabalho, os três primeiros métodos também foram utilizados como referência na elaboração do método utilizado aqui para o desenvolvimento desta pesquisa.

O método proposto para avaliação ergonômica do ambiente urbano, desenvolvido por Mülfarth (2017), considera duas etapas, uma quantitativa e outra qualitativa. $\mathrm{Na}$ primeira etapa (quantitativa), são avaliados os aspectos físicos do ambiente, dentro de determinados parâmetros que podem estar ou não presentes no espaço a ser analisado.

Os critérios analisados foram:

1. Ciclovias - melhor situação, com a presença de ciclovia ou ciclofaixa; situação regular, com a presença de ciclorrota na via (indica possibilidade de ciclistas na área) e pior situação, em vista da ausência de qualquer tipo de infraestrutura ao ciclista (observação).

2. Estacionamento - melhor situação, com a ausência de estacionamento ao longo da via; situação regular, em que se permite que os carros estacionem em pelo menos um dos lados da via e pior situação, em que os carros estacionam dos dois lados da via e há presença de estacionamentos na área (observação).

3. Uso misto do solo - a melhor situação é uma área com diversos usos do solo; a situação regular tem pelo menos dois tipos de uso do solo e a pior situação dispõe de apenas um uso do solo (observação).

4. Presença de atrativos verdes - a melhor situação, sendo visível uma grande predominância de vegetação na área; situação regular, com presença de vegetação na área e pior situação, quando a vegetação é praticamente ausente na área (observação).

5. Proximidade aos meios de transporte coletivo Os parâmetros sugeridos empregam uma distância a pé de $300 \mathrm{~m}$ até o transporte coletivo, o que equivale a aproximadamente 5 minutos de caminhada. Não foram consideradas as distâncias até a estação de metrô, pois não há este modal em Lorena. A medição do local até o ponto de ônibus é a forma de avaliação, e os parâmetros se adequam a melhor situação, com distância ao ponto de ônibus de até $150 \mathrm{~m}$; situação regular, com distância de até $300 \mathrm{~m}$ e pior situação, com distância ao ponto de ônibus superior a $300 \mathrm{~m}$.

6. Dimensionamento das calçadas - Medição da largura é a forma de medição, e os parâmetros são, melhor situação, calçada dimensionada acima do mínimo necessário $+10 \mathrm{~cm}$; situação regular com a calçada dimensionada até o mínimo necessário +10 $\mathrm{cm}$ e a pior situação, em que a calçada está dimensionada abaixo do mínimo necessário.

7. Velocidade das vias - O parâmetro de pior situação foi adaptado à velocidade máxima 
encontrada nos espaços de avaliação. A forma de avaliação é a medição da velocidade dos veículos, com a melhor situação no limite de $30 \mathrm{~km} / \mathrm{h}$; situação regular no limite de $40 \mathrm{~km} / \mathrm{h}$ e pior situação no limite de $50 \mathrm{~km} / \mathrm{h}$ ou mais.

8. Percepção do espaço - A forma de avaliação é baseada na observação, medição e análise fotográfica; o parâmetro de melhor situação contempla a presença de muito verde, calçada de tamanho adequada, recuo dos prédios permitindo ampla visão do céu e baixo fluxo de caros; situação regular, com presença regular de verde, visão da abóbada celeste afetada pelos edifícios e fluxo de carro médio ou alto e, por fim, a pior situação, com ausência de verde, calçada subdimensionada, visão restringida do céu e alto fluxo de carros.

Os critérios 9. Fluxo de carros; 10. Fluxo de pedestres e 11. Fluxo de bicicletas têm como forma de avaliação a medição (contagem de carros, pedestres e bicicletas, respectivamente, na via por hora. Se utilizam do parâmetro de 0 a 500 carros, pessoas ou bicicletas/hora - 1 ícone; 501 a 1000 carros, pessoas ou bicicletas/hora - 2 ícones; 1001 a 1500/hora - 3 ícones e de 1501 ou mais carros, pedestres ou bicicletas por hora -4 ícones.

Os parâmetros de melhor situação, situação regular e pior situação, são indicados, respectivamente, pelos símbolos nas cores verde, amarelo e vermelho nos quadros de resumo que serão mostrados mais à frente no capítulo 2 .

$\mathrm{Na}$ segunda etapa (qualitativa), o conteúdo avaliado foi desenvolvido a partir da percepção do usuário sobre o espaço. Entrevistas, questionários e escalas de avaliação foram as ferramentas utilizadas nesta parte. De modo resumido, as escalas de avaliação foram apresentadas e subdivididas em 5 categorias - péssimo, ruim, regular, bom e ótimo - que ilustram a opinião dos pedestres em relação ao espaço da calçada, além de questioná-los sobre a frequência que utilizam ou passam pelo local. É importante ressaltar que as escalas de avaliação da etapa qualitativa têm como finalidade correlacionar os resultados das entrevistas ou questionários com valores preestabelecidos em normas, na legislação ou aferidos no local. Essa correlação também possibilita a avaliação conjunta dos aspectos de desempenho ergonômico e o conforto ambiental como um todo. Os questionários são formulados a partir de perguntas sobre como o usuário se sente e qual seu grau de satisfação em relação aos parâmetros estabelecidos.

A pesquisa consistiu em avaliar os aspectos dos segmentos de calçada de acordo com o método de observação e inquirição, proposto na tese de livre docência de Kronka Mülfarth (2017); que, partindo da escolha do ambiente urbano, utiliza-se de análises quantitativas e qualitativas para desenvolver melhor avaliação do ambiente, identificar os problemas encontrados e propor melhorias para cada local.

A região central do município de Lorena, São Paulo, foi escolhida para construção desta pesquisa em razão de sua condição monocêntrica e intensa atividade comercial e econômica, bem como em virtude da relevância da elaboração de pesquisas acerca do espaço urbano em cidades de médio porte. Para aplicação deste método, os trechos foram determinados a partir de observação durante diferentes horários e dias, considerando vias cuja movimentação apresentava grande impacto visual. Os trechos escolhidos também correspondem a espaços urbanos com presença de equipamentos institucionais, públicos e privados, de características distintas, contudo, de fundamental uso pela população.

Foram escolhidos 4 (quatro) segmentos de ruas, sendo todos com metragem inferior a $250 \mathrm{~m}$. O primeiro trecho fica localizado na Rua Dom Bosco, no segmento de quadra da UNISAL (Centro Universitário Salesiano de São Paulo) e do Colégio São Joaquim. O segundo trecho, também na Rua Dom Bosco, abrange a quadra da Santa Casa de Lorena e também do AME (Ambulatório Médico de Especialidades). O terceiro trecho se estabelece na Rua Dr. Rodrigues de Azevedo, próxima também a Santa Casa e AME e principal rua de acesso ao centro da cidade. O quarto e último trecho a ser analisado encontra-se na Rua Comendador Custódio Vieira, compreendendo a Escola Estadual Gabriel Prestes e o prédio da Secretaria Municipal de Educação de Lorena.

\subsection{Aplicação na Rua Dom Bosco - Trecho 1}

O trecho 1 é rota de grande parte dos veículos que saem do centro histórico em direção a outros bairros; seu fluxo de carros e pedestres é ininterrupto e se intensifica nos horários de entrada e saída de alunos, tanto do colégio quanto da faculdade. Os critérios de uso do solo e proximidade aos meios de transporte são positivos, com diversidade de uso do solo na área e distância de $128 \mathrm{~m}$ do ponto central de medição até o ponto de ônibus, respectivamente; porém não há nenhum equipamento de proteção para espera do passageiro de ônibus. Os estacionamentos, presença de verde, velocidade da via e percepção do espaço se enquadram na situação regular dos parâmetros. Já a ciclovia e a qualidade do passeio são possuem avaliação negativa, visto que mesmo com movimentação de ciclistas no trecho, há ausência de infraestrutura adequada e a calçada é insuficiente para atender o fluxo de pedestres que recebe.

A vegetação do local está inserida nas dependências do colégio e da Igreja São Benedito. É visível e oferece conforto visual no trecho que, assim como os prédios do local, não afeta a visão da abóboda celeste; contudo, a vegetação não proporciona 
sombra na calçada. As calçadas do trecho 1 possuem larguras de 1,87 $\mathrm{m}$ do lado direito e 1,55 m do lado esquerdo; e mesmo com números que sejam relativamente adequados para uma calçada, se mostram insatisfatórias em períodos de grande fluxo de pessoas. A circulação de pedestres é prejudicada pelo estacionamento de bicicletas ao lado de postes e lixeiras na calçada, falta espaço no passeio livre quando há permanência de pessoas aguardando transporte e tendo encontros casuais, também devido a presença de irregularidades no piso, variação de tipos de piso, buracos, lixeiras e inúmeras placas de sinalização.

Durante as medições foi percebida a dificuldade de deslocamento de uma pessoa com deficiência física, que, conforme observado, reproduzia barulho semelhante a uma buzina de automóvel para conseguir se locomover com sua cadeira de rodas em meio a outros pedestres. A travessia de uma calçada a outra era dificultada pelo estacionamento de veículos na via, falta de rampas de acessibilidade, conexão e espaço de calçada (Tabela 1).

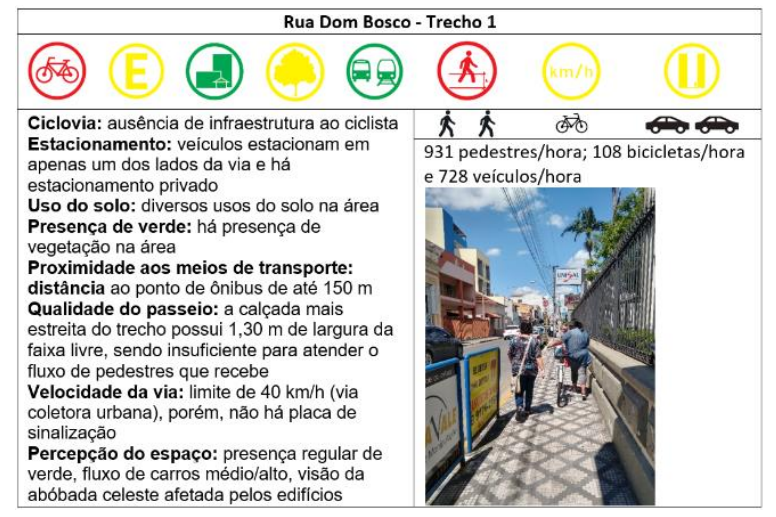

Tabela 1: Tabela Síntese dos questionários aplicados no Trecho 1. Fonte: Elaborado pela autora.

Neste trecho foram entrevistadas 52 pessoas; o maior número de respostas foi no período entre 12:00 - 13:00, e a maior parte do questionário foi respondido pelo público feminino, com idades entre 25 e 31 anos. A utilização do automóvel foi a opção mais votada, seguido dos deslocamentos a pé. A percepção do usuário no geral foi satisfatória, porém aspectos como ruído, risco de atropelamento, vegetação, falta de lixeiras e bancos, aspectos gerais, largura e piso da calçada tiveram avaliações negativas, (Tabela 2).

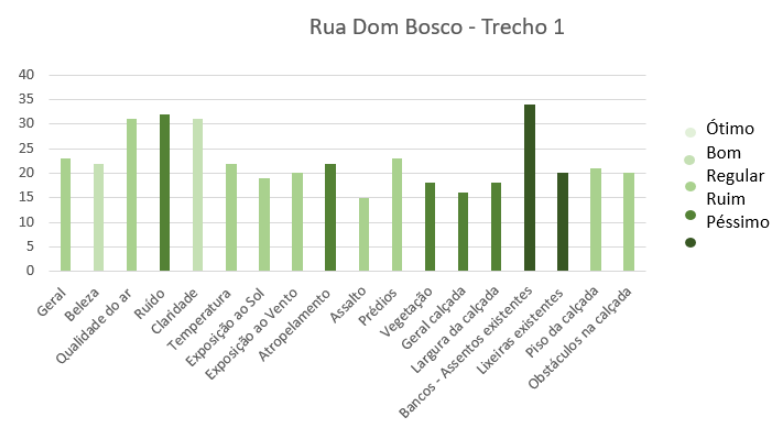

Tabela 2: Gráfico 1 - Respostas dos questionários do Trecho 1. Fonte: Elaborado pela autora.

\subsection{Aplicação na Rua Dom Bosco - Trecho 2}

Grande parte do fluxo de veículos do trecho 2 é proveniente do centro histórico (passando pelo trecho 1) bem como do centro oeste e centro sul. Há fluxo regular de pedestres e bicicletas, e o horário das $17 \mathrm{~h}$ apresenta o maior fluxo de carros no trecho. $\mathrm{O}$ uso do solo e a velocidade da via são positivamente avaliados, com diversidade de usos e limite de $30 \mathrm{~km} / \mathrm{h}$ respectivamente. Há presença de vegetação na área (nas dependências da escola Conde Moreira Lima), os carros podem estacionar em pelo menos um dos lados da via; a distância ao ponto de ônibus é de até $300 \mathrm{~m}$ e a percepção do espaço é regular. Assim como no trecho 1, a ausência de ciclovia e a baixa qualidade do passeio são aspetos negativos do local, muitos pacientes do AME e do Pronto Socorro aguardam o atendimento na calçada, atrapalhando o fluxo de pedestres, que preferem caminhar pelo leito carroçável, colocando em risco suas vidas. Também é possível notar obstáculos no piso das calçadas, largura quase insuficiente do passeio livre para pessoas obesas e PCD em cadeira de rodas (Tabela 3 ) com lixeiras dificultando a passagem e falta de rampas conectando os dois lados da via; não há sinalização tátil de alerta e direcional neste trecho, mesmo com equipamentos de saúde amplamente utilizados pela população do município e de outras cidades.

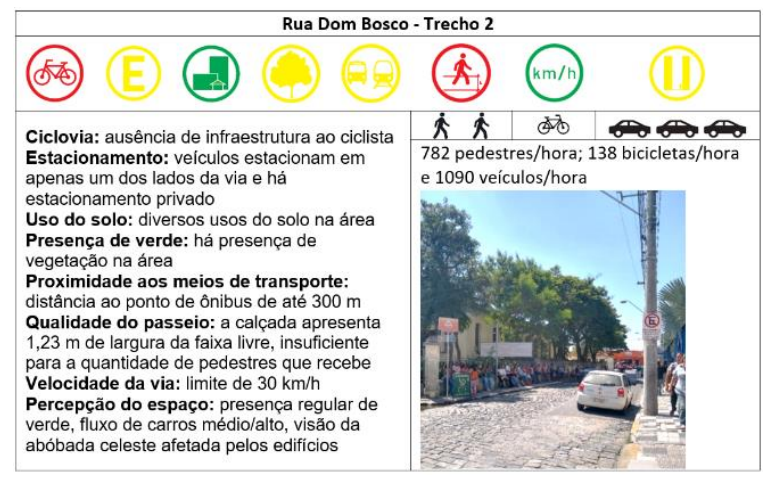

Tabela 3: Tabela Síntese dos questionários aplicados no Trecho 2. Fonte: Elaborado pela autora.

Neste trecho foram entrevistadas 37 pessoas, o horário das 12:00 - 13:00 é o que retrata maior quantidade de pessoas, contabilizando maioria dos 
entrevistados sendo público feminino, com idade entre 26 e 31 anos, que utilizam majoritariamente o transporte por automóvel e em seguida o deslocamento a pé. No geral, a avaliação varia de regular a insatisfatória; a falta de beleza, alto nível de ruído, risco de assalto, escassez de vegetação, bancos e lixeiras; qualidade ruim da largura e do piso da calçada e os obstáculos encontrados nela são fatores desagradáveis que superam os aspectos positivos, (Tabela 4).

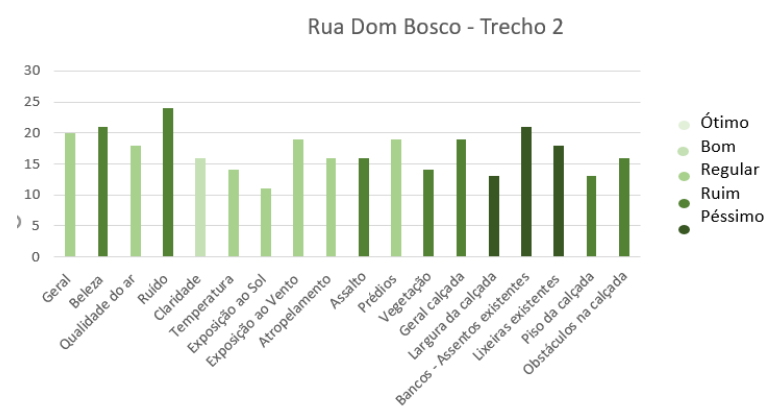

Tabela 4: Gráfico 2 - Respostas dos questionários do Trecho 2. Fonte: Elaborado pela autora.

\subsection{Aplicação na Rua Dr. Rodrigues de Azevedo - Trecho 3}

A Rua Dr. Rodrigues de Azevedo se mostrou a mais movimentada entre as demais, em todos os fluxos considerados na análise. O fluxo de pedestres, bicicletas e veículos é regular com maior movimentação nos horários das $10 \mathrm{~h}, 12 \mathrm{~h}$ e $17 \mathrm{~h}$, respectivamente. $\mathrm{O}$ único critério avaliado positivamente é a diversidade de usos do solo na área. Estacionamento, proximidade aos meios de transporte, velocidade da via e percepção do espaço são consideradas no parâmetro de situação regular. Critérios como ciclovia, presença de verde e qualidade do passeio receberam avaliações negativas (Tabela 5), dado que, respectivamente, não há infraestrutura adequada ao ciclista, há ausência de vegetação na área e a largura da faixa livre é insuficiente para atender os pedestres, é frequente ver pessoas esbarrando umas nas outras por falta de espaço, e também não há conexão entre as calçadas.

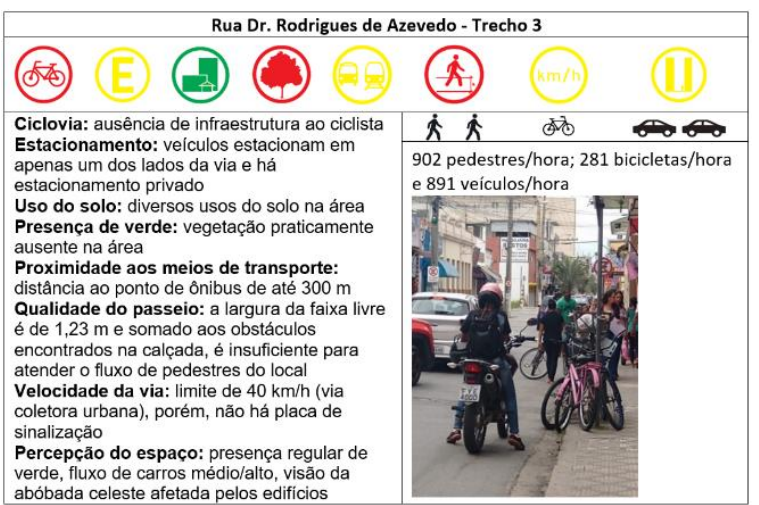

Tabela 5: Tabela Síntese dos questionários aplicados no Trecho 3. Fonte: Elaborado pela autora.

Trinta e quatro pessoas responderam ao questionário, grande parte delas passa pelo local próximo do horário das 12:00 e 13:00. A partir disso, é possível dizer que no geral, a idade mais representada varia entre 26 e 31 anos e que aproximadamente $70 \%$ dos entrevistados se declaram mulheres. 0 modal de transporte mais utilizado é o deslocamento a pé, seguido do uso de automóvel. Em geral, a avaliação do trecho é regular com tendência ao insatisfatório. Risco de atropelamento; obstáculos na calçada; inexistência de vegetação, bancos e lixeiras; piso e largura da calçada tiveram péssima avaliação. Falta de beleza, aspectos gerais da calçada, risco de assalto e alto nível de ruído também receberam avaliação negativa, (Tabela 6).

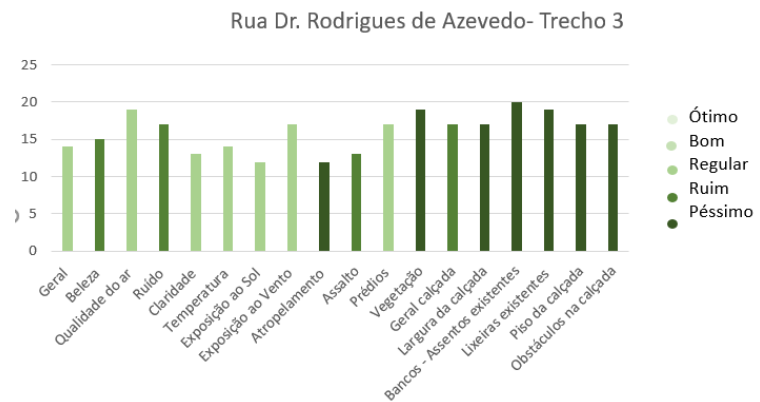

Tabela 6: Gráfico 3 - Respostas dos questionários do Trecho 3. Fonte: Elaborado pela autora.

\subsection{Aplicação na Rua Comendador Custódio Vieira- Trecho 4}

No geral, o trecho em questão se mostrou menos movimentado em comparação com os demais locais analisados. $\mathrm{O}$ horário das $12 \mathrm{~h}$ é o mais movimentado para pedestres, ciclistas e veículos; o local possui um ponto de ônibus inserido a aproximadamente $20 \mathrm{~m}$ do ponto central de medição, também apresenta diversos usos do solo na área, sendo estes dois, os critérios positivos do local. Como situação regular, temos a presença de verde, estacionamento e a percepção do espaço. Os critérios com avaliados como pior situação são a ausência de ciclovia, o limite de velocidade da via e a qualidade do passeio, insuficiente para o fluxo de pedestres, (Tabela 7). 


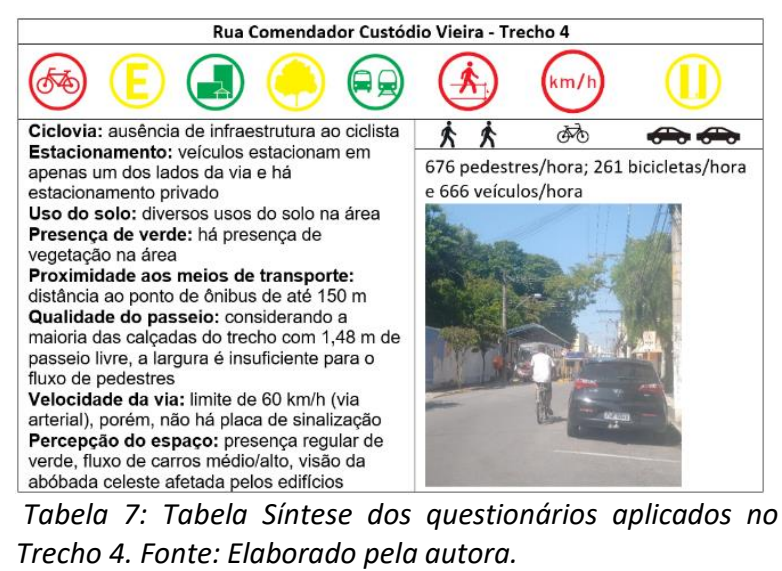

Com 27 entrevistas, $70 \%$ de resposta do público feminino, idade variando de 26 a 31 anos, maior movimentação no período das 17:00 às 18:00 e uso do automóvel superior ao deslocamento peatonal; aparentemente a percepção do usuário no geral é regular, com propensão à insatisfação. A vegetação do local divide opiniões, é, ao mesmo tempo, votada como regular e insatisfatória, considerando que, no local há só um canteiro com vegetação, pois a parte mais arborizada está inserida no jardim da Escola Estadual Gabriel Prestes. Aspectos como falta de beleza, alto nível de ruído, risco de assaltos, prédios em demasia, obstáculos e largura da calçada são vistos como desagradáveis, (Tabela 8).

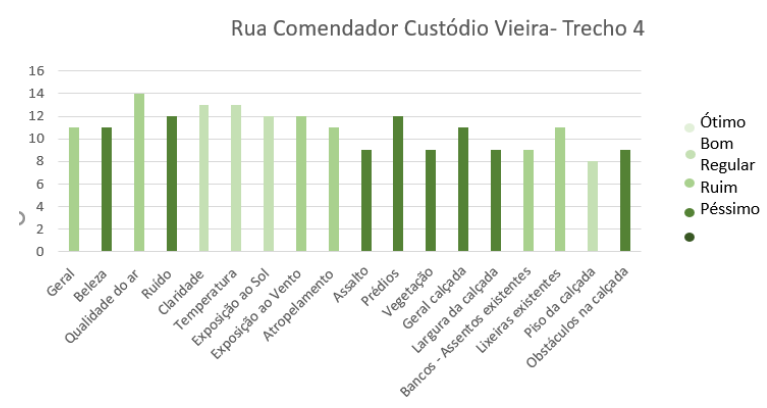

Tabela 8: Gráfico 4 - Respostas dos questionários do Trecho 4. Fonte: Elaborado pela autora.

\section{CONCLUSÃO}

Beleza, risco de atropelamento e assalto, ausência de vegetação, características gerais da calçada, largura, obstáculos encontrados nela e ausência de bancos e lixeiras são, no geral, os fatores mais desagradáveis nos trechos analisados. Também pela quantidade de entrevistas realizadas em cada trecho, pode-se considerar que há mais pessoas frequentando os trechos 1, 2 e 3 em comparação ao trecho 4. A falta de arborização e condições ruins nas características das calçadas nos trechos analisados reflete a insatisfação das pessoas que passam pelo local com determinada frequência. A ausência da arborização urbana pode indicar também, o interesse limitado na participação e apropriação das pessoas nos espaços públicos.

No contexto urbano, o paisagismo é um ator importante para tornar os ambientes mais convidativos e atraentes na escala do pedestre, proporcionando então maior interesse das pessoas em passar pelo local, bem como permanecer ali por algum tempo. A insuficiência da arborização e de espaço na calçada, junto ao grande número de veículos que transitam no local, somado ao asfalto existente na maior parte das ruas desta região, contribuem para o aumento da sensação térmica nestes ambientes, acrescido de uma provável piora na qualidade do ar (também devido aos engarrafamentos nos horários de fluxo intenso de veículos).

Fatores como os aqui levantados, que se relacionam diretamente à percepção do usuário, devem ser levados em conta não só na melhoria dos espaços urbanos, em especial os percursos pedonais, como também devem ser base de diretrizes para planos de melhoria de áreas urbanas que tenham como objetivo principal melhorias quanto à caminhabilidade. Os percursos aqui avaliados, refletem grande parte dos percursos da área central do município de Lorena, e também se alinham ao encontrado em muitos municípios com a mesma escala. A questão do pedestre deve ser uma diretriz básica no planejamento e na gestão das cidades. Neste contexto, o uso da vegetação, é parte integrante e necessária nestas diretrizes.

\section{REFERÊNCIAS}

1. ORGANIZAÇÃO DAS NAÇÕES UNIDAS (ONU) (2018). World Urbanization Prospects. Nova lorque.

2. INSTITUTO BRASILEIRO DE GEOGRAFIA E ESTATístICA (IBGE) (2010). Mapa do censo demográfico. Disponível em https://www.ibge.gov.br/estatisticas/sociais/populac ao/9662-censo-demografico-

2010.html?edicao=9673\&t=destaques. Acesso em: 05 de novembro de 2020.

SOUTHWORTH, M. (2005). Designing the Walkable City. In: Journal of Urban Planning and Development (C) Asce.

3. GEHL, J. (2015). Cidades para pessoas. São Paulo: Perspectiva.

4. CARVALHO, M. V. S. de A. (2006). Um modelo para dimensionamento de calçadas considerando o nível de satisfação do pedestre. Tese de doutorado apresentada à Escola de Engenharia de São Carlos da Universidade de São Paulo. São Carlos.

5. KRONKA MÜLFARTH, R. C. (2017). Proposta metodológica para avaliação ergonômica do ambiente urbano: a inserção da ergonomia no ambiente construído. FAUUSP, São Paulo. Tese para Livre Docência. 